\title{
Relação entre a produtividade do mamoeiro e o déficit hídrico (ky) na região Norte Fluminense ${ }^{1}$
}

\author{
Robson P. Posse ${ }^{2}$, Salassier Bernardo ${ }^{3}$, Elias F. de Sousa ${ }^{3}$, Messias G. Pereira ${ }^{4}$, Pedro H. Monnerat ${ }^{5}$ \& Romildo D. Gottardo ${ }^{6}$
}

\begin{abstract}
RESUMO
Teve-se como objetivo neste trabalho, determinar o coeficiente de resposta ao déficit hídrico na produção de frutos comerciais e totais do mamoeiro, cultivado na região Norte do Estado do Rio de Janeiro. O experimento foi realizado na área de convênio UENF/PESAGRO-RIO, no município de Campos dos Goytacazes, RJ, no período de 25/04/2006 a 18/05/2007, utilizando-se o mamoeiro cultivar Híbrido UENF/CALIMAN01 e um delineamento em blocos casualizados, com cinco tratamentos, correspondendo às reposições de 50\% (T1), 75\% (T2), 100\% (T3), 125\% (T4) e 150\% (T5) da evapotranspiração de referência (ETo), com quatro repetições. A máxima produção comercial real da cultura, aos 13 meses de cultivo e com quatro meses de colheita, foi de 38,78 $\mathrm{t} \mathrm{ha}^{-1}$ (T3) e a máxima produção total real encontrada foi de 49,42 t ha- ${ }^{-1}$ (T5). O mamoeiro cultivar Híbrido UENF/CALIMAN01 conduzido até os 13 meses de cultivo e com quatro meses de colheita, apresentou um coeficiente de resposta de produção (ky) para frutos comerciais de 1,4581 e para produção total um coeficiente igual a 0,5674.
\end{abstract}

Palavras-chave: Carica papaya L., coeficientes de sensibilidade, deficiência hídrica

\section{Response coefficient of papaya yield to water stress (ky) in Northern Rio de Janeiro}

\begin{abstract}
The objective of this study was to determine the response coefficient to water stress in the commercial and total yield of papaya fruits grown in the northern region of the State of Rio de Janeiro. The experiment was conducted in an area of UENF/PESAGRO-RIO in the municipality of Campos dos Goytacazes, Rio de Janeiro, from 25/04/2006 to 18/05/2007, using the papaya cultivar Hybrid UENF/CALIMAN01. The experiment had a randomized block design with five treatments [replacement of reference evapotranspiration (ETo) by 50\% (T1), 75\% (T2), 100\% (T3), 125\% (T4) and 150\% (T5)], with four replications. The highest real commercial yield of the crop after 13 months of growth and four harvest months was $38.78 \mathrm{tha}^{-1}$ (T3) and the highest total real yield was $49.42 \mathrm{t} \mathrm{ha}^{-1}$ (T5). After 13 months of growth and 4 harvest months of the papaya cultivar Hybrid UENF/CALIMAN01 the response coefficient for commercial fruit yield (ky) was 1.4581 and 0.5674 for total yield.
\end{abstract}

Key words: Carica papaya L., sensitivity coefficients, water deficit

1 Parte da Tese de Doutorado em Produção Vegetal do primeiro autor pela UENF

2 Doutorando, Bolsista CAPES, LEAG/UENF, Av. Alberto Lamego 2000, Pq. Califórnia, CEP 28013-602, Campos dos Goytacazes, RJ. Fone/Fax: (22) $2726-1543$. E-mail: posse@uenf.br

3 DEA/UENF, Fone/Fax: (22) 2726-1543. E-mail: salassier@uenf.br; efs@uenf.br

${ }^{4}$ Departamento de Fitomelhoramento/UENF, Fone: (22) 2726-1428. E-mail: messias@uenf.br

${ }^{5}$ Departamento de Fitotecnia/UENF, Fone: (22) 2726-1425. E-mail: monnerat@uenf.br

${ }^{6}$ Técnico Agrícola LEAG/UENF, Fone/Fax: (22) 2726-1543. E-mail: rdgottardo@yahoo.com.br 


\section{INTRODUÇÃO}

Tendo em vista a importância dos efeitos do manejo hídrico sobre a produtividade de uma cultura entre os métodos de quantificação da produtividade em função do efeito hídrico na planta, o coeficiente de resposta da produção ou índice de sensibilidade ao déficit hídrico (ky) se vem destacando. Pesquisas já foram realizadas com o objetivo de determinar o ky em algumas culturas, tais como no café (Arruda \& Grande, 2003; Picini et al., 1999), na batata (Bezerra et al., 1999), no feijão (Carvalho et al., 2000) e no quiabo (Paes, 2003), porém para a cultura do mamoeiro não se tem informação a respeito do ky.

O déficit hídrico na cultura influencia a evapotranspiração e o seu rendimento. Define-se evapotranspiração real (ETr) e evapotranspiração máxima (ETm) como os valores de evapotranspiração que, ao longo do ciclo total de uma cultura, realmente ocorreram e o que poderia ser atingido potencialmente com ótimas condições de cultivo, respectivamente (Doorenbos \& Kassam, 1979).

Para predizer a redução da produtividade de uma cultura quando submetida a um estresse hídrico, Doorenbos \& Kassam (1979) propuseram um modelo com base na penalização da produtividade potencial da cultura, em função da relação ETr/ETm ocorrida durante o seu ciclo.

A razão ETr/ETm indica o suprimento hídrico fornecido à planta em relação à sua necessidade potencial (Yao, 1969). Uma relação inferior à unidade pode indicar que a cultura ficou sujeita a um estresse hídrico.

O rendimento máximo de uma cultura (Ym) é aquele obtido com uma variedade altamente produtiva e bem adaptada ao respectivo ambiente de crescimento, cultivada em condições em que não haja limitação de fatores como água, nutrientes, pragas e doenças, durante seu cultivo até o amadurecimento (Doorenbos \& Kassam, 1979); em geral, a diminuição na produtividade ocasionada por déficit hídrico durante o período vegetativo e de maturação, é relativamente pequena, enquanto durante o florescimento e os períodos de formação da produtividade será grande (Allen et al., 1998).

A utilização do ky para planejamento, dimensionamento e operação de áreas irrigadas, permite ao produtor avaliar o efeito da lâmina de irrigação e definir sua utilização, em termos de rendimento e produção total da cultura. A sensibilidade das culturas ao suprimento de água (ky) pode ser assim classificada: baixo $(\mathrm{ky}<0,85)$; baixo/médio $(0,85<\mathrm{ky}<1,00)$; médio/alto $(1,00<\mathrm{ky}<1,15)$ e alto (ky $>1,15)$ (Doorenbos \& Kassam, 1979).

Considerando-se a necessidade de maiores informações sobre a sensibilidade da cultura do mamoeiro em relação ao fornecimento de água objetivou-se, com este experimento, determinar o coeficiente de resposta (ky) na produção de fru- tos comerciais e produção total do mamoeiro, cultivado na região Norte do Estado do Rio de Janeiro.

\section{MATERIAL E MÉTODOS}

O experimento foi realizado na Estação Evapotranspirométrica do CCTA/UENF, localizada a $21^{\circ} 45^{\prime}$ de latitude Sul, $41^{\circ} 18$ ' de longitude Oeste e 11 metros de altitude, na área de convênio UENF/E. E. C. PESAGRO-RIO, no município de Campos dos Goytacazes, região norte do Estado do Rio de Janeiro, no período de 25/04/2006 a 18/05/2007, com o mamoeiro (Carica papaya L.) da variedade Híbrido UENF/ CALIMAN01 plantado em fileiras simples e espaçamento de 3,0 x 3,0 m (representando por planta, uma área de 9,00 m²). O clima da região, segundo classificação de Köppen, é do tipo Aw, ou seja, tropical úmido, com inverno seco e chuvas máximas no verão. O solo da área experimental é um Cambissolo de origem fluvial, pouco profundo, com drenagem moderada a imperfeita; apresenta, como características físicas, capacidade de campo igual a 12,3\% (em peso), ponto de murcha permanente igual a $6,4 \%$ (em peso) e densidade aparente igual a $1,81 \mathrm{~g} \mathrm{~cm}^{-3}$. O fator de disponibilidade (f) para a cultura do mamoeiro foi considerado 0,5 e a profundidade de exploração $80 \%$ de suas raízes de $0,3 \mathrm{~m}$, conforme recomendado por Bernardo et al. (1996); desta forma, o limite de água disponível no solo para a cultura do mamão foi de $32 \mathrm{~mm}$, na camada de $0-30 \mathrm{~cm}$; as características físicas e químicas do solo da área experimental estão apresentadas nas Tabelas 1 e 2 .

Instalou-se o experimento através de um delineamento em blocos casualizados, com cinco tratamentos (lâminas de irrigação), correspondendo às reposições de 50\% (T1), 75\% (T2), 100\% (T3), 125\% (T4) e 150\% (T5) da evapotranspiração de referência (ETo - Penman-Monteith FAO (Allen et al., 1998)), com quatro repetições. Cada parcela experimental era formada de uma única planta.

As mudas foram preparadas em tubetes de $115 \mathrm{~cm}^{3}$, utilizando-se substrato em mistura com adubo (formulação NPK 14-14-14) na quantidade de 500 g para cada $25 \mathrm{~kg}$ de substrato. O preparo do solo na área de cultivo ocorreu 60 dias antes do transplantio das mudas e se constituía de aração, gradagem e posterior aplicação e incorporação de calcário

Tabela 1. Características físicas do solo da área experimental na camada de $0-0,3 \mathrm{~m}$ de profundidade

\begin{tabular}{|c|c|c|c|c|c|}
\hline \multicolumn{6}{|c|}{ Granulometria } \\
\hline \multicolumn{4}{|c|}{ Areias (\%) } & \multirow{2}{*}{$\begin{array}{c}\text { Silte } \\
\%\end{array}$} & \multirow{2}{*}{$\begin{array}{c}\text { Argila } \\
\%\end{array}$} \\
\hline Grossa & Média & Fina & Total & & \\
\hline 16 & 34 & 28 & 78 & 3 & 19 \\
\hline
\end{tabular}

Tabela 2. Características químicas do solo da área experimental na camada de $0-0,3 \mathrm{~m}$ de profundidade

\begin{tabular}{|c|c|c|c|c|c|c|c|c|c|c|c|c|c|c|c|c|c|c|c|c|}
\hline \multirow[t]{2}{*}{$\mathrm{pH}$} & $P *$ & $\mathrm{~K}^{*}$ & $\mathrm{Ca}$ & $\mathrm{Mg}$ & Al & $\mathrm{H}+\mathrm{Al}$ & $\mathrm{Na}$ & \multirow{2}{*}{$\begin{array}{l}\text { C } \\
\%\end{array}$} & \multirow{2}{*}{$\begin{array}{c}\mathrm{MO} \\
\mathrm{g} \mathrm{dm^{-3 }}\end{array}$} & S.B. & $T$ & $t$ & m & V & $\mathrm{Fe}$ & $\mathrm{Cu}$ & $\mathrm{Zn}$ & Mn & $S$ & B \\
\hline & \multicolumn{2}{|c|}{$\mathrm{mg} \mathrm{dm^{-3 }}$} & \multicolumn{5}{|c|}{$\mathrm{cmol}_{\mathrm{c}} \mathrm{dm}^{-3}$} & & & \multicolumn{3}{|c|}{$\mathrm{cmol}_{\mathrm{c}} \mathrm{dm}^{-3}$} & \multicolumn{2}{|c|}{$\%$} & \multicolumn{6}{|c|}{$\mathrm{mg} \mathrm{dm^{-3 }}$} \\
\hline 4,3 & 6 & 10 & 0,9 & 0,5 & 0,0 & 2,8 & 0,02 & 0,67 & 11,6 & 1,4 & 4,2 & 1,4 & 0 & 34 & 68,0 & 1,4 & 9,2 & 5,5 & 8,2 & 0,58 \\
\hline
\end{tabular}


dolomítico, na quantidade de 1,2 t ha ${ }^{-1}$ necessária, de acordo com a análise do solo, para uma elevação da saturação de base a $80 \%$. O transplantio foi realizado em camalhões com altura de aproximadamente $60 \mathrm{~cm}$ enquanto as mudas foram transplantadas para o campo no dia 25/04/2006, ocasião em que atingiram altura aproximada de $20 \mathrm{~cm}$; três mudas foram transplantadas por cova (em distribuição triangular de 30 x 30 × $30 \mathrm{~cm}$ ) e a sexagem ocorreu aos 84 dias após o transplantio (DAT).

Na cova de plantio se aplicaram $15 \mathrm{~L}$ de esterco de curral curtido (10 L na formação da cova e $5 \mathrm{~L}$ na linha, entre plantas, no momento da sexagem), 600 g de superfosfato simples e $60 \mathrm{~g}$ de cloreto de potássio; aos 30 DAT foram aplicados $30 \mathrm{~g} \mathrm{cova}^{-1}$ de sulfato de amônio e, aos 90 DAT, $100 \mathrm{~g} \mathrm{cova}^{-1}$ de sulfato de amônio, $100 \mathrm{~g} \mathrm{cova}^{-1}$ de superfosfato simples e $50 \mathrm{~g} \mathrm{cova}^{-1}$ de cloreto de potássio.

O nitrogênio e o potássio foram aplicados mensalmente utilizando-se o sulfato de amônia (com 20\% de N) e o cloreto de potássio (com $60 \%$ de $\mathrm{K}_{2} \mathrm{O}$ ) como fontes; nos quarto, quinto e sexto meses após o transplantio, 20 g planta $^{-1}$ de $\mathrm{N}$ e 36 g planta $^{-1}$ de $\mathrm{K}_{2} \mathrm{O}$ foram aplicados e do sétimo mês em diante, 30 g planta $^{-1}$ de $\mathrm{N}$ e 48 g planta $^{-1}$ de $\mathrm{K}_{2} \mathrm{O}$. Aplicaram-se os micronutrientes no sexto mês, na quantidade de $20 \mathrm{~g}$ planta $^{-1}$, utilizando-se como fonte o fertilizante MIB3 (1,8\% B, 0,8\% Cu, 3,0\% Fe, 2,0\% Mn, 0,1\% Mo e 9,0\% Zn).

Durante a condução do experimento o controle de ervas daninhas, pragas e doenças, foi realizado seguindo-se os tratos culturais apropriados para a cultura do mamão, conforme recomendado por Marin et al. (1995).

Definiram-se as lâminas de irrigação de cada tratamento em função da evapotranspiração da cultura (ETc = ETo x kc), em que a quantidade de água a ser reposta durante a semana foi tida como sendo o somatório da evapotranspiração da cultura da semana anterior ( $\Sigma$ ETc) multiplicado pelo fator de reposição (fa), referente a cada tratamento. Realizaramse as irrigações três vezes por semana, nas segunda, quarta e sextas-feiras, em que o total de déficit da semana anterior era dividido entre as três irrigações.

A evapotranspiração de referência (ETo) foi estimada pelo método de Penman-Monteith FAO, através de uma estação climatológica instalada a poucos metros do local do experimento, da marca Thies Clima, modelo DL-15. Os valores do coeficiente da cultura $(\mathrm{kc})$ utilizados em dias após transplantio (DAT), foram de 0,8 entre 0 a 120 DAT, 1,0 entre 121 a 180 DAT e 1,2 após 180 DAT.

O volume total de água aplicado por tratamento foi determinado pela seguinte equação:

$$
\mathrm{V}=\{(\mathrm{ETo} \times \mathrm{kc} \times \mathrm{fa})-\mathrm{Pe}\} \times \mathrm{Np} \times \mathrm{Ap} \times \mathrm{PW} \times \frac{1}{\mathrm{Ea}}
$$

donde:

$$
\begin{aligned}
& \text { V - volume de água a ser aplicado por tratamento, } \mathrm{L} \\
& \text { ETo - evapotranspiração de referência, mm } \\
& \text { kc - coeficiente cultural no período, adimensional } \\
& \text { fa - fator de aplicação dos tratamentos }(0,5 ; 0,75 ; \\
& \quad 1,0 ; 1,25 \text { e } 1,5)
\end{aligned}
$$

Pe - precipitação efetiva entre duas irrigações, mm

$\mathrm{Np}$ - número de plantas a serem irrigadas, adimensional

Ap - área ocupada por planta, $\mathrm{m}^{2}$

PW - porcentagem de área sombreada ou molhada, o que for maior, decimal

Ea - eficiência de aplicação do sistema, em decimal

Foi considerada precipitação efetiva (Pe) a lâmina de água utilizada para elevar o conteúdo de água no solo até a capacidade de campo.

Como o balanço hídrico era semanal, o volume total de água reposto à cultura para cada tratamento foi definido fa-

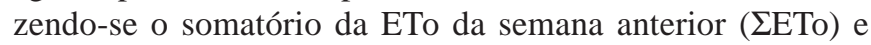
se levando em consideração cada tratamento (fa) descontando-se o somatório da precipitação efetiva entre duas irrigações, ficando:

$$
\mathrm{V}=\left\{\left(\sum \mathrm{ETo} \times \mathrm{kc} \times \mathrm{fa}\right)-\sum \mathrm{Pe}\right\} \times \mathrm{Np} \times \mathrm{Ap} \times \mathrm{PW} \times \frac{1}{\mathrm{Ea}}
$$

Antes de se iniciar os tratamentos, os quais tiveram início no dia 24/07/2006 (90 DAT), as irrigações eram uniformes em todo o experimento com base na demanda evapotranspirométrica estimada para a cultura. Para os tratamentos T1, T2, T4 e T5, a irrigação foi implementada de forma manual, colocando-se as respectivas quantidades de água necessária em recipientes (bombonas de 50 L), uma para cada tratamento, os quais disponibilizavam a água de forma uniforme e gradual, simulando um gotejador na planta. Para o tratamento T3 utilizou-se o sistema de irrigação por gotejamento, fazendo-se uso de um gotejador auto-regulável por planta, com vazão de $8 \mathrm{~L} \mathrm{~h}^{-1}$.

Com o início da maturação (18/01/2007, aos 268 DAT), os frutos foram colhidos semanalmente, devidamente identificados e separados, de acordo com sua classificação, em frutos comerciais e não comerciais. Consideraram-se frutos comerciais os que apresentaram peso igual ou maior a $800 \mathrm{~g}$ e frutos não comerciais os menores que $800 \mathrm{~g}$. Os frutos foram colhidos quando atingiam o estádio I de maturação, conforme identificação apresentada por Tatagiba \& Oliveira (2000).

A última colheita ocorreu no dia 18/05/2007, aos 388 DAT, juntamente com o término do experimento, o que representou o total de quatro meses de colheita e aproximadamente 13 meses de cultivo da cultura.

Para o cálculo do coeficiente de resposta da cultura ao déficit hídrico (ky), utilizou-se o modelo descrito por Doorenbos \& Kassam (1979) (Eq. 3) e, para a estimativa da disponibilidade hídrica da cultura, o método do balanço hídrico diário (Eq. 4). A ETm foi calculada pela Eq. 5 e a ETr pela Eq. 6 (Allen et al., 1998).

$$
\left(1-\frac{\mathrm{Yr}}{\mathrm{Ym}}\right)=\mathrm{ky} \cdot\left(1-\frac{\mathrm{ETr}}{\mathrm{ETm}}\right)
$$

em que: Yr é o rendimento real obtido em t ha-1, Ym o rendimento máximo obtido em tha-1, ky o coeficiente de resposta da cultura, ETr a evapotranspiração real total, em mm e ETm a evapotranspiração máxima total, em mm. 


$$
\Theta_{i}=\Theta_{i-1}+I_{i}+P_{i}-E a_{i}
$$

Com as seguintes condições de contorno:

se: $\Theta_{\mathrm{i}}<0$, então $\Theta_{\mathrm{i}}=0$

se: $\Theta_{\mathrm{i}}>$ CTA, então $\Theta_{\mathrm{i}}=$ CTA

donde:

$\Theta_{\mathrm{i}}$ - lâmina de água no solo no dia i, mm

$\Theta_{\mathrm{i}-1}$ - lâmina de água no solo no dia anterior (i-1), mm

$\mathrm{I}_{\mathrm{i}}$ - irrigação aplicada no dia i, mm

$\mathrm{P}_{\mathrm{i}}$ - precipitação ocorrida no dia $\mathrm{i}, \mathrm{mm}$

$\mathrm{ETa}_{\mathrm{i}}$ - evapotranspiração real da cultura ocorrida no dia i, mm

$$
\begin{aligned}
& \mathrm{ETm}=\sum_{\mathrm{i}=1}^{\mathrm{N}} \mathrm{ETo}_{\mathrm{i}} \times \mathrm{kc}_{\mathrm{i}} \\
& \mathrm{ETr}=\sum_{\mathrm{i}=1}^{\mathrm{N}} \mathrm{ETo}_{\mathrm{i}} \times \mathrm{kc}_{\mathrm{i}} \times \mathrm{ks}_{\mathrm{i}}
\end{aligned}
$$

sendo:

$\mathrm{N}$ - número de dias total do ciclo do experimento, 388 dias

$\mathrm{ETo}_{\mathrm{i}}$ - evapotranspiração de referência ocorrida no dia i, mm

$\mathrm{Kc}_{\mathrm{i}}$ - coeficiente cultural no dia i, adimensional

$\mathrm{Ks}_{\mathrm{i}}$ - coeficiente de umidade do solo no dia i, adimensional

$$
\left(\mathrm{Ks}_{\mathrm{i}}=\frac{\ln \left(\mathrm{LAA}_{\mathrm{i}}+1\right)}{\ln \left(\mathrm{CTA}_{\mathrm{i}}+1\right)}\right)
$$

$\mathrm{LAA}_{\mathrm{i}}$ - lâmina de água atual do solo no dia i, mm $\mathrm{CTA}_{\mathrm{i}}$ - capacidade total de água do solo no dia i, mm

\section{RESULTADOS E DISCUSSÃO}

A Tabela 3 apresenta os valores totais e/ou mensais das variáveis climáticas para cada mês de cultivo do mamoeiro (de 25/04/06 a 18/05/07); ressalta-se que as precipitações aqui apresentadas se referem a totais mensais mas que elas não ocorreram uniformemente durante o mês, principalmente no mês de janeiro, com precipitações diárias que ultrapassaram a capacidade total de água que o solo consegue reter (CTA); como exemplo, só no dia 03/01/2007 choveu $82 \mathrm{~mm}$.

Apresentam-se na Tabela 4, os valores totais da evapotranspiração de referência das precipitações totais, efetivas e excedentes, da irrigação realizada, do total de lâmina aplicada e o total da evapotranspiração máxima da cultura durante o período de avaliação para os diversos tratamentos realizados; nota-se que nos tratamentos em que a quantidade de água aplicada foi além da lâmina referencial para manejo de irrigação (T3), as precipitações efetivas se tornaram cada vez menores, haja vista que, no tratamento T5, apenas 2,73 mm foram considerados precipitação efetiva.

Mesmo se fazendo uso de reposições hídricas em termos de manejo e acima do valor da evapotranspiração de referência, os tratamentos T4 e T5 sofreram deficiência hídrica
Tabela 3. Evapotranspiração de referência mensal (ETo, mm mês $\left.{ }^{-1}\right)$, precipitação total mensal (Prec, mm mês ${ }^{-1}$ ), temperaturas do ar média (Tmed, $\left.{ }^{\circ} \mathrm{C}\right)$, máxima $\left(\operatorname{Tmax},{ }^{\circ} \mathrm{C}\right)$ e mínima $\left(\operatorname{Tmín},{ }^{\circ} \mathrm{C}\right)$ mensal, umidade relativa média mensal (URméd, \%), radiação solar média mensal ( $\left.R s, \mathrm{~W} \mathrm{~m}^{-2}\right)$ e velocidade do vento médio mensal a $2 \mathrm{~m}$ de altura ( $\mathrm{u} 2, \mathrm{~m} \mathrm{~s}^{-1}$ ), durante o período de condução da cultura do mamoeiro UENF/CALIMAN01

\begin{tabular}{lcrrrrrrrr}
\hline Mês & Dias & \multicolumn{1}{c}{ ETo } & \multicolumn{1}{c}{ Prec } & Tmed & Tmáx & Tmín & URméd & Rs & u2 \\
abr/06 & 5 & 18,65 & 7,00 & 23,0 & 28,2 & 19,2 & 79,5 & 162,9 & 1,4 \\
mai/06 & 31 & 95,24 & 14,20 & 21,0 & 26,9 & 16,5 & 74,5 & 161,4 & 1,7 \\
jun/06 & 30 & 84,00 & 28,30 & 20,0 & 25,8 & 15,6 & 76,8 & 151,9 & 1,8 \\
ju/06 & 31 & 90,89 & 15,70 & 19,7 & 27,3 & 14,3 & 79,1 & 151,6 & 1,5 \\
ago/06 & 31 & 116,03 & 38,00 & 21,1 & 27,3 & 16,8 & 78,3 & 176,1 & 2,3 \\
set/06 & 30 & 119,39 & 42,20 & 20,9 & 26,2 & 17,0 & 76,6 & 181,2 & 2,7 \\
out/06 & 31 & 129,05 & 121,80 & 22,4 & 27,1 & 19,4 & 82,3 & 208,6 & 2,6 \\
nov/06 & 30 & 129,17 & 207,40 & 23,4 & 28,2 & 20,5 & 84,2 & 209,3 & 2,5 \\
dez/06 & 31 & 144,54 & 84,40 & 24,7 & 29,9 & 21,2 & 83,1 & 226,8 & 2,2 \\
jan/07 & 31 & 126,64 & 430,10 & 24,5 & 29,5 & 21,5 & 88,9 & 203,3 & 1,9 \\
fev/07 & 28 & 146,03 & 50,30 & 25,5 & 30,8 & 21,6 & 79,9 & 282,7 & 1,5 \\
mar/07 & 31 & 133,35 & 19,30 & 26,4 & 33,0 & 21,4 & 76,3 & 277,3 & 1,9 \\
abr/07 & 30 & 89,53 & 65,70 & 24,8 & 30,2 & 20,5 & 83,2 & 111,1 & 1,6 \\
mai/07 & 18 & 49,26 & 3,60 & 22,0 & 28,3 & 17,4 & 77,7 & 85,4 & 1,9 \\
\hline Média/ & & & & 22,8 & 28,5 & 18,8 & 80,0 & 185,0 & 2,0 \\
Total & 388 & 1471,79 & 1128,00 & & & & & & \\
\hline
\end{tabular}

em pelo menos uma fase ou época de seu desenvolvimento. As lâminas aplicadas, que correspondem à evapotranspiração real da planta em todos os tratamentos, foram menores que a evapotranspiração máxima que a cultura poderia atingir (Tabela 4).

Em virtude do experimento ter sido realizado em condições de campo, as chuvas fizeram com que os tratamentos fossem alterados na lâmina aplicada, o que era para representar 50\% da ETo (T1) acabou, no final do experimento, representando $71,27 \%$ da ETo e, nos tratamentos T2, T3, T4 e T5 corresponderam, ao término do experimento, a 85,64, 96,05, 99,26 e 100,50\% da ETo respectivamente.

A máxima produção comercial real da cultura do mamoeiro cultivar Híbrido UENF/CALIMAN01 aos 13 meses de cultivo e com quatro meses de colheita, foi obtida no tratamento T3, com 38,78 t ha-1 (Tabela 5) e a máxima produção total real encontrada foi no tratamento T5, com 49,42 tha-1 (Tabela 6). A produção comercial foi bem próxima à encontrada por Marinho (2007), ou seja, de 39,88 $\mathrm{t} \mathrm{ha}^{-1}$, para o mesmo período de colheita (quatro meses), com a mesma

Tabela 4. Valores totais da evapotranspiração de referência (ETo), das precipitações totais $(\mathrm{Pt})$, efetivas (Pe) e excedentes (Pex), da irrigação realizada (I), do total de lâmina aplicada (ETr) e o total da evapotranspiração máxima da cultura (ETm) durante o período de avaliação para os diversos tratamentos realizados na cultura do mamoeiro Híbrido UENF/CALIMAN01

\begin{tabular}{lrrrrrrr}
\hline \multirow{2}{*}{ Tratamento } & ETo & Pt & Pe & Pex & I & ETr & ETm \\
\cline { 2 - 8 } & \multicolumn{5}{c}{ mm } \\
T1 (50\% ETo) & 1471,79 & 1128 & 666,44 & 461,56 & 382,55 & 1048,99 & 1571,41 \\
T2 (75\% ETo) & 1471,79 & 1128 & 609,97 & 518,03 & 650,55 & 1260,52 & 1571,41 \\
T3 (100\% ETo) & 1471,79 & 1128 & 468,48 & 659,52 & 945,19 & 1413,67 & 1571,41 \\
T4 (125\% ETo) & 1471,79 & 1128 & 256,67 & 871,33 & 1204,29 & 1460,96 & 1571,41 \\
T5 (150\% ETo) & 1471,79 & 1128 & 2,73 & 1125,28 & 1476,39 & 1479,12 & 1571,41 \\
\hline
\end{tabular}


variedade e cultivados na região Norte do Espírito Santo que, segundo o IBGE (2007), é a segunda maior região produtora de mamão do Brasil.

A produtividade máxima comercial encontrada para a cultura do mamoeiro foi de 44,54 tha ${ }^{-1}$, enquanto a produtividade máxima total foi de 49,91 t ha-1. Em relação à produção total de cada tratamento, 45,70\% representaram a produção não comercial no tratamento T1, assim como 25,61, $14,83,19,50$ e $29,57 \%$ indicaram a produção não comercial para os tratamentos T2, T3, T4 e T5, respectivamente. Pôdese observar que, com uma aplicação e/ou reposição hídrica menor, a planta produziu mais frutos não comerciais e, a medida em que se foi incrementando o fornecimento hídrico até uma lâmina de 1413,67 mm (T3) a quantidade de frutos não comerciais se foi reduzindo representando, assim, a lâmina que produziu uma quantidade menor de frutos não comerciais. Aplicações superiores às do tratamento T3, fizeram com que novamente ocorresse um aumento de frutos não comerciais.

Um déficit hídrico acentuado ocasiona atraso no desenvolvimento do mamoeiro reduzindo a taxa de crescimento do caule e das folhas, além de poder provocar queda das flores ou estímulo à produção de flores estéreis (Bernardo et al., 1996; Coelho et al., 1999). O efeito do déficit hídrico na produção comercial pôde ser notado, ressaltando-se que uma redução de 33,24\% do fornecimento hídrico ocasionou queda de $51,13 \%$ na produtividade comercial (Tabela 5).

Tabela 5. Valores totais da lâmina aplicada (ETr), da evapotranspiração máxima da cultura (ETm), do déficit de evapotranspiração relativa (1 - ETr/ETm), da produção real comercial (Yrc), da produção máxima comercial (Ymc) e da queda de rendimento relativo (1 - Yrc/Ymc) nos diversos tratamentos realizados na cultura do mamoeiro Híbrido UENF/ CALIMAN01

\begin{tabular}{|c|c|c|c|c|c|c|}
\hline Tratamento & $\begin{array}{c}\text { ETr } \\
(\mathrm{mm})\end{array}$ & $\begin{array}{l}\text { ETm } \\
(\mathrm{mm})\end{array}$ & (1-ETr/ETm) & $\begin{array}{l}\text { Yrc } \\
\left(t \mathbf{h a}^{-1}\right)\end{array}$ & $\begin{array}{l}\text { Ymc } \\
\left(t \mathrm{ha}^{-1}\right)\end{array}$ & (1-Y \\
\hline (J) (J0) LIO) & 1048,99 & 1571,41 & 27 & 21,77 & 44,54 & 0 \\
\hline T2 (75 & 1260,52 & 1571,41 & 0,1978 & 33,94 & 44,54 & 0,2381 \\
\hline T3 (100\% ETo) & 1413,67 & 1571,41 & 0,1004 & 38,78 & 44,54 & 0,1294 \\
\hline T4 (125\% ETo) & 1460,96 & 1571,41 & 0,0703 & 38,17 & 44,54 & 0,1431 \\
\hline T5 (150\% ETo) & 1479,12 & 1571,41 & 0,0587 & 34,81 & 44,54 & 0,2186 \\
\hline
\end{tabular}

Para determinação do coeficiente de resposta ao déficit hídrico - ky, para a produção comercial do mamoeiro foi excluído do cálculo o tratamento T5, pelo fato de que não se pode atribuir a redução da Yrc neste tratamento apenas ao déficit hídrico mas, também, a eventos de umidificação excessiva do solo e, conseqüentemente, à falta de oxigenação das raízes e à provável lixiviação de nutrientes. A inclusão deste tratamento poderia acarretar uma interpretação errônea; assim, para obtenção do valor do coeficiente ky da Eq. 3, utilizou-se um procedimento de otimização matemática em que o valor de Ymc foi alcançado quando o intercepto da regressão linear entre a queda de rendimento relativo (1 - Yrc/Ymc) e o déficit de evapotranspiração relativa
(1 - ETr/ETm) foi igual a zero. Utilizando-se deste procedimento, o coeficiente de inclinação da regressão linear equivaleu ao valor de ky, que foi de 1,4581 , apresentando um coeficiente de determinação $\left(\mathrm{R}^{2}\right)$ igual a 0,945 (Figura 1). O modelo foi significativo a $5 \%$ de probabilidade.

De acordo com Doorenbos \& Kassam (1979), o valor de ky maior que 1 demonstra que a planta é sensível ao déficit hídrico. No caso do mamoeiro, em se tratando da produção comercial a planta demonstrou que é altamente sensível ao déficit hídrico $(\mathrm{ky}=1,4581)$.

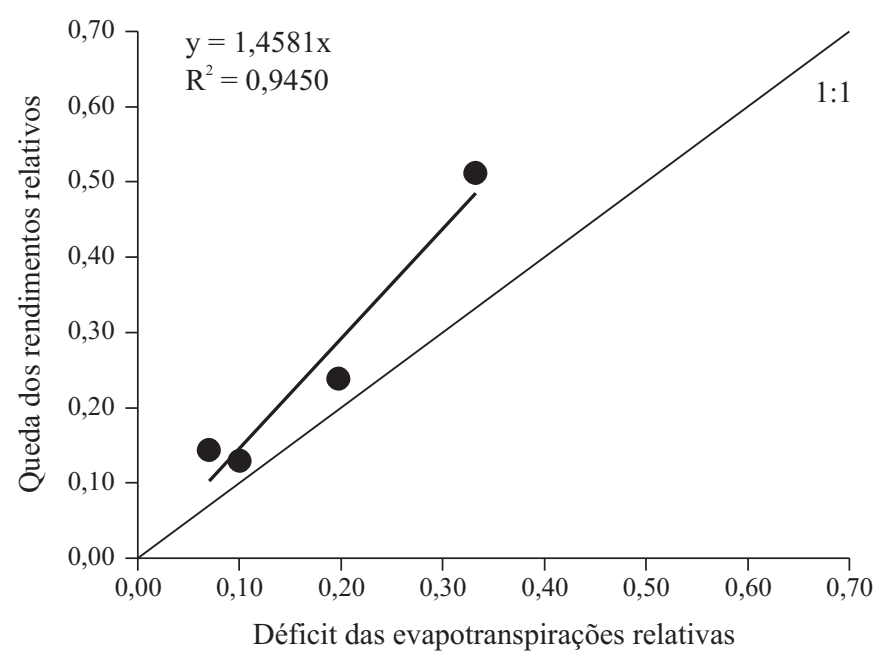

Figura 1. Relação entre o déficit das evapotranspirações relativas e a queda dos rendimentos relativos na produção comercial do mamoeiro cultivar HÍBRIDO UENF/CALIMAN01

Na Tabela 6 é possível observar o efeito do déficit hídrico na produção total do mamoeiro. Uma redução de 33,24\% do fornecimento hídrico resultou em queda de 19,69\% na produtividade total.

Na determinação do ky para a produção total do mamoeiro utilizou-se o mesmo procedimento de otimização matemática descrita anteriormente, na determinação do ky para a produção comercial. Nota-se, em termos de produção total, que a produção foi crescente, juntamente com os tratamentos (Tabela 6); assim, utilizando-se os cinco tratamentos, pôde-se determinar o valor do ky, que foi de 0,5674, apresentando um coeficiente de determinação $\left(\mathrm{R}^{2}\right)$ igual a 0,8777 e significativo a $5 \%$ de probabilidade (Figura 2). Em se tratando de produção total, o mamoeiro possui baixa sensibilidade ao déficit hídrico $(\mathrm{ky}<0,85)$, de acordo com a classificação proposta por Doorenbos \& Kassam (1979), porém o que gera receita para o produtor é a produção comercial e não a total; logo, no intuito de alcançar maior rentabilidade, ou seja, maior índice de frutos comerciais, o produtor deve realizar um manejo adequado de reposição hídrica, de forma a não deixar a planta passar por déficit hídrico, pois o mamoeiro é sensível ao déficit hídrico na produção de frutos comerciais, não se esquecendo de que o manejo da irrigação, na medida do possível, também deve evitar o excesso de água no solo, seja por irrigação ou por chuvas. 
Tabela 6. Valores totais da lâmina aplicada (ETr), da evapotranspiração máxima da cultura (ETm), do déficit de evapotranspiração relativa (1 - ETr/ETm), da produção real total (Yrt), da produção máxima total (Ymt) e da queda de rendimento relativo (1 - Yrt/Ymt) nos diversos tratamentos realizados na cultura do mamoeiro Híbrido UENF/ CALIMAN01

\begin{tabular}{lcccrcc}
\hline Tratamento & $\begin{array}{c}\text { ETr } \\
(\mathbf{m m})\end{array}$ & $\begin{array}{c}\text { ETm } \\
(\mathbf{m m})\end{array}$ & $\begin{array}{c}\text { (1-ETr/ETm) } \\
\text { (t ha-1) }\end{array}$ & $\begin{array}{c}\text { Ymt } \\
(\mathbf{t} \text { ha-1) }\end{array}$ & (1-Yrt/Ymt) \\
T1 (50\% ETo) & 1048,99 & 1571,41 & 0,3324 & 40,09 & 49,91 & 0,1969 \\
T2 (75\% ETo) & 1260,52 & 1571,41 & 0,1978 & 45,62 & 49,91 & 0,0860 \\
T3 (100\% ETo) & 1413,67 & 1571,41 & 0,1004 & 45,53 & 49,91 & 0,0879 \\
T4 (125\% ETo) & 1460,96 & 1571,41 & 0,0703 & 47,41 & 49,91 & 0,0502 \\
T5 (150\% ETo) & 1479,12 & 1571,41 & 0,0587 & 49,42 & 49,91 & 0,0099 \\
\hline
\end{tabular}

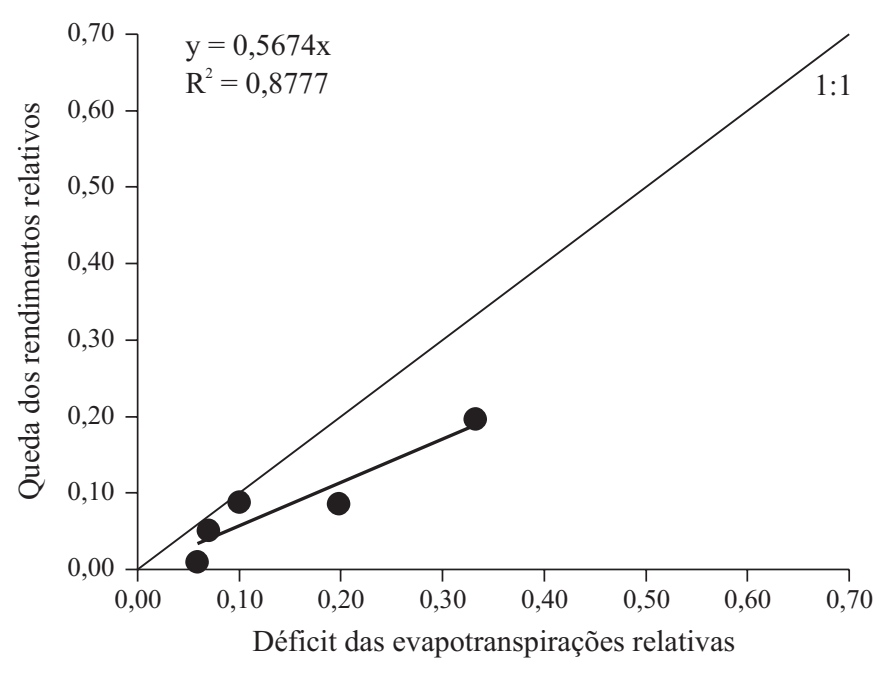

Figura 2. Relação entre o déficit das evapotranspirações relativas e a queda dos rendimentos relativos na produção total do mamoeiro cultivar HÍBRIDO UENF/CALIMAN01

Alguns pesquisadores, como Awada (1961), Awada et al. (1979) e Aiyelaagbe et al. (1986) afirmam que, em relação à produção comercial, o mamoeiro é muito sensível ao déficit de umidade no solo. Silva (1999) e Awada et al. (1979) observaram, em relação à lâmina de água aplicada, que o incremento da produtividade total foi menor que o da produtividade comercial. À medida em que se aumenta a lâmina de água aplicada tem-se um aumento da relação entre produtividade comercial e produtividade total (Silva, 1999). Esta característica pode explicar a ausência de diferenças significativas entre a produtividade comercial e total em relação à lâmina aplicada, observada por Marinho (2007), ao se aplicar tratamentos que variaram de 50 a $130 \%$ da ETo, com excesso de chuva no ciclo da cultura.

Todos esses trabalhos citados, mesmo sendo alguns com cultivares diferentes e conduzidos em épocas e locais diferentes, vêm a corroborar com os resultados aqui já apresentados para o mamoeiro, porém mais pesquisas devem ser realizadas em diferentes regiões e tratamentos, a fim de que se possa apoiar os valores aqui encontrados para o coeficiente de resposta (ky) do mamoeiro, tanto para a produção comercial como para a produção total.

\section{CONCLUSÕES}

1. O mamoeiro cultivar Híbrido UENF/CALIMAN01 conduzido até os 13 meses de cultivo e com quatro meses de colheita, apresentou um coeficiente de resposta de produção (ky) para frutos comerciais de 1,4581 (sensibilidade alta) e para produção total, um coeficiente igual a 0,5674 (sensibilidade baixa).

\section{LITERATURA CITADA}

Aiyelaagbe, I. O. O.; Fawsi, M. O. A.; Babalola, O. Growth, development and yield of pawpaw (Carica papaya L.) 'Homestead selection' in response to soil moisture stress. Plant and Soil, v.93, p.427-435, 1986.

Allen, R. G.; Pereira, L. S.; Raes, D.; Smith, M. Crop evapotranspiration - guidelines for computing crop water requirements. Rome: FAO, 1998. 300p. Irrigation and Drainage, 56

Arruda, F. B.; Grande, M. A. Fator de resposta da produção do cafeeiro ao déficit hídrico em Campinas. Bragantia, v.62. n.1, p.139-145, 2003.

Awada, M. Soil moisture tension in relation to fruit types of papaya plants. Hawaii Farm Science, v.10, n.2, p.7-8, 1961.

Awada, M.; Wu, I. P.; Suehisa, R. H.; Padgett, M. M. Effects of drip irrigation and fertilization on vegetative growth, fruit yield, and mineral composition of the petioles and fruits of papaya. Honolulu: Hawaii Agricultural Experiment Station, University of Hawaii, 1979. 20p. Boletim Técnico, 103

Bernardo, S.; Carvalho, J. A.; Sousa, E. F. Irrigação do mamoeiro. Campos dos Goytacazes: UENF, 1996. 20p. Boletim Técnico, 5

Bezerra, F. M. L.; Angelocci, L. R.; Minami, K. Coeficientes de sensibilidade ao déficit hídrico para a cultura da batata nas condições edafoclimáticas da região de Piracicaba, SP. Revista Brasileira de Engenharia Agrícola e Ambiental, v.3, n.3, p.322326, 1999.

Carvalho, J. A.; Pereira, G. M.; Andrade, M. J. B.; Roque, M. W. Efeito do déficit hídrico sobre o rendimento do feijão caupí (Vigna unguiculata (L.) Walp). Ciência e Agrotecnologia, v.24, n.3, p.710-717, 2000.

Coelho, E. F.; Silva, J. G. F.; Souza, L. F. S. Irrigação e fertirrigação. In: Sanches, N. F., Dantas, J. L. L. (coords.) O cultivo do mamão. Cruz das Almas: Embrapa Mandioca e Fruticultura, 1999. cap.7, p.32-41. Circular Técnica, 34

Doorenbos, J.; Kassam, A. H. Yield response to water. Irrigation and Drainage Paper 33. Rome: Food and Agriculture Organization of the United Nations, 1979. 193p.

IBGE - Instituto Brasileiro de Geografia e Estatística. http:// www.sidra.ibge.gov.br/ 25 Mai. 2007.

Marin, S. L. D.; Gomes, J. A.; Salgado, J. S.; Martins, D. S.; Fullin, E. A. Recomendações para a cultura do mamoeiro dos grupos solo e formosa no estado do Espírito Santo. 4.ed. Vitória: EMCAPA, 1995. 57p. Circular Técnica, 3

Marinho, A. B. Respostas dos mamoeiros cultivar golden e do HÍBRIDO UENF/CALIMAN01 sob diferentes lâminas de irrigação e doses de potássio. Campos dos Goytacazes: UENF, 2007. 125p. Tese Doutorado 
Paes, H. M. F. Demanda hídrica e função de produção da cultura do quiabeiro (Abelmoschus esculentus (L.) Moench) em Campos do Goytacazes, RJ. Campos dos Goytacazes: UENF, 2003. 57p. Dissertação Mestrado

Picini, A. G.; Camargo, M. B. P.; Ortolani, A. A.; Fazuoli, L. C.; Gallo, P. B. Desenvolvimento e teste de modelos agrometeorológicos para a estimativa de produtividade do cafeeiro. Bragantia, v.58, n.1, p.157-170, 1999.
Silva, J. G. F. Efeitos de diferentes lâminas e freqüências de irrigação sobre o desenvolvimento e a produtividade do mamoeiro (Carica papaya L.). Viçosa: UFV, 1999. 90p. Tese Doutorado

Tatagiba, J. S.; Oliveira, A. A. R. Tratamentos pós-colheita. In: Ritzinger, C. H. S. P.; Souza, J. S. Mamão: Fitossanidade. Cruz das Almas: Embrapa Mandioca e Fruticultura. Brasília: Embrapa Comunicação para Transferência de Tecnologia, 2000. cap.2, p.12-14.

Yao, A. Y. M. The R index for plant water requirements. Agricultural Meteorology, v.6, n.4, p.259-273, 1969. 